\title{
La guerra con Estados Unidos y la crisis del pensamiento mexicano*
}

Charles A. Hale

El autor revisa las dramáticas repercusiones de la guerra contra Estados Unidos entre los medios intelectuales mexicanos y destaca la polémica entre los diarios conservadores y liberales a propósito del desenlace del conflicto.

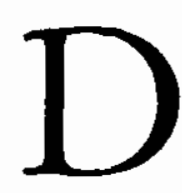
espués de una escaramuza fronteriza en el río Grande, el 25 de abril de 1846, México y Estados Unidos entraron en guerra y en pocos meses las tropas de Zacarias Taylor habían penetrado el norte alcanzando Monterrey y Saltillo. Al mismo tiempo, una expedición a cargo de Windfield Scott arribó a Veracruz, se encaminó al interior siguiendo el viejo camino de los conquistadores, y llegó a las afueras de la ciudad de México en agosto de 1847. La resistencia de los mexicanos fue heroica y determinante en algunas partes, pero la desorganización y un liderazgo inapropiado causaron estragos en cada intento de defensa nacional. La capital cayó y fue ocupada por los invasores, el gobier- no mexicano huyó a Querétaro y un ignominioso tratado de paz fue negociado y aceptado por los indefensos mexicanos, aunque no sin una seria oposición por parte del elemento radical (puro) que proponía resistir hasta la muerte. Debido al rápido sometimiento y a la pérdida de más de la mitad de su territorio, la alguna vez optimista y orgullosa nación de Iturbide quedó sacudida y se tornó hacia la amarga reflexión sobre su presente es-

- Titulo original: "The war with the United States and the crisis in mexican thought", The Americas, Washington, Academy of American Franciscan History, vol. xix, núm 2, octubre de 1975, pp. 153-173. Traducción de Ana Claudia Morales Viramontes. 
tado y la flagrante exposición de sus debilidades al enfrentarse con una pequeña y no muy eficiente fuerza invasora.

La propia independencia de México se veía ahora amenazada. La fácil victoria del poderoso vecino significaba que México podría ser absorbido por Estados Unidos en cualquier momento, especialmente cuando había ya un movimiento con ese propósito preparándose al norte del río Grande. ${ }^{1}$ El optimismo de los primeros días de la república había desaparecido. El impacto del desastre militar después de una lúgubre década de mediocridad y agotadoras revoluciones militares, acentuaron la crisis del pensamiento mexicano. Tanto liberales como conservadores veían ahora la necesidad de imponer cambios radicales en el curso del México independiente. A partir de la caída del gobierno radical de Gómez Farías en 1834, el país había permanecido a la deriva, y cuando los americanos lo invadieron, su vigor parecía haber desaparecido. A pesar de la presencia de un partido moderado considerable, las distintas facciones agudizaron sus diferencias como nunca había sucedido en la historia de la república, excepto quizá en el año de 1832. Liberales y conservadores apelaban a sus programas tradicionales para dar soluciones a la crisis mexicana de 1847 , y se diseminaron las semillas de un gran conflicto.

A la inversa de la década precedente a la guerra, los años de 1846 a 1853 fueron testigos de una gran agitación intelectual

\footnotetext{
' Véase John Douglas Pitts Fuller, The movement for the acquisition of all Mexico, 1846-1848, Baltimore, 1936. El autor agradece la colaboración de la Fundación Doherty que hizo posible esta investigación.
}

en el país. Al mismo tiempo que los mexicanos comenzaron a investigar las causas de la vergonzosa derrota de 1847 , su pensamiento se amplió hasta incluir las preguntas básicas que sólo habían sido tratadas antes por unos cuantos pensadores sobresalientes. Aparecieron muchos periódicos y revistas que fueron órganos de difusión de opiniones inteligentes y a veces profundas. Antes de la guerra las revistas tenían poco que ver con la política y eran por lo común superficiales. Ahora había cuatro grandes diarios y un sinnúmero de periódicos menores. Todos tenían un formato grande (distinción que antes de 1846 sólo tenía El Siglo $X L X)$ y contenían cuatro páginas de noticias y opiniones. El Monitor Republicano representaba el punto de vista radical de los liberales; El Siglo $X L X$ (fundado en 1841, suspendido en 1846 y reanudado en 1848) fue el órgano de los liberales moderados. El Tiempo (1846) y El Universal (de 1848) eran portavoces de los conservadores. Los pensadores vanguardistas utilizaban la página editorial para expresar sus opiniones, y puesto que sus artículos aparecían sin firma sólo podemos adivinar su origen.

Esta es la época de la monumental Historia de Méjico de Lucas Alamán, de los escritos de Cuevas y Tornel, y de numerosos panfletos de considerable importancia. Ante la crisis, los hombres no podían seguir dejando de lado los problemas de México.

Con la aparición de $E l$ Tiempo, en enero de 1846, hubo un gran debate que abrazaba las premisas básicas de la independencia, y que continuó hasta más allá de 1853. Rara vez un artículo que expresara las posiciones conservadoras o radicales aparecía sin una fuerte réplica 


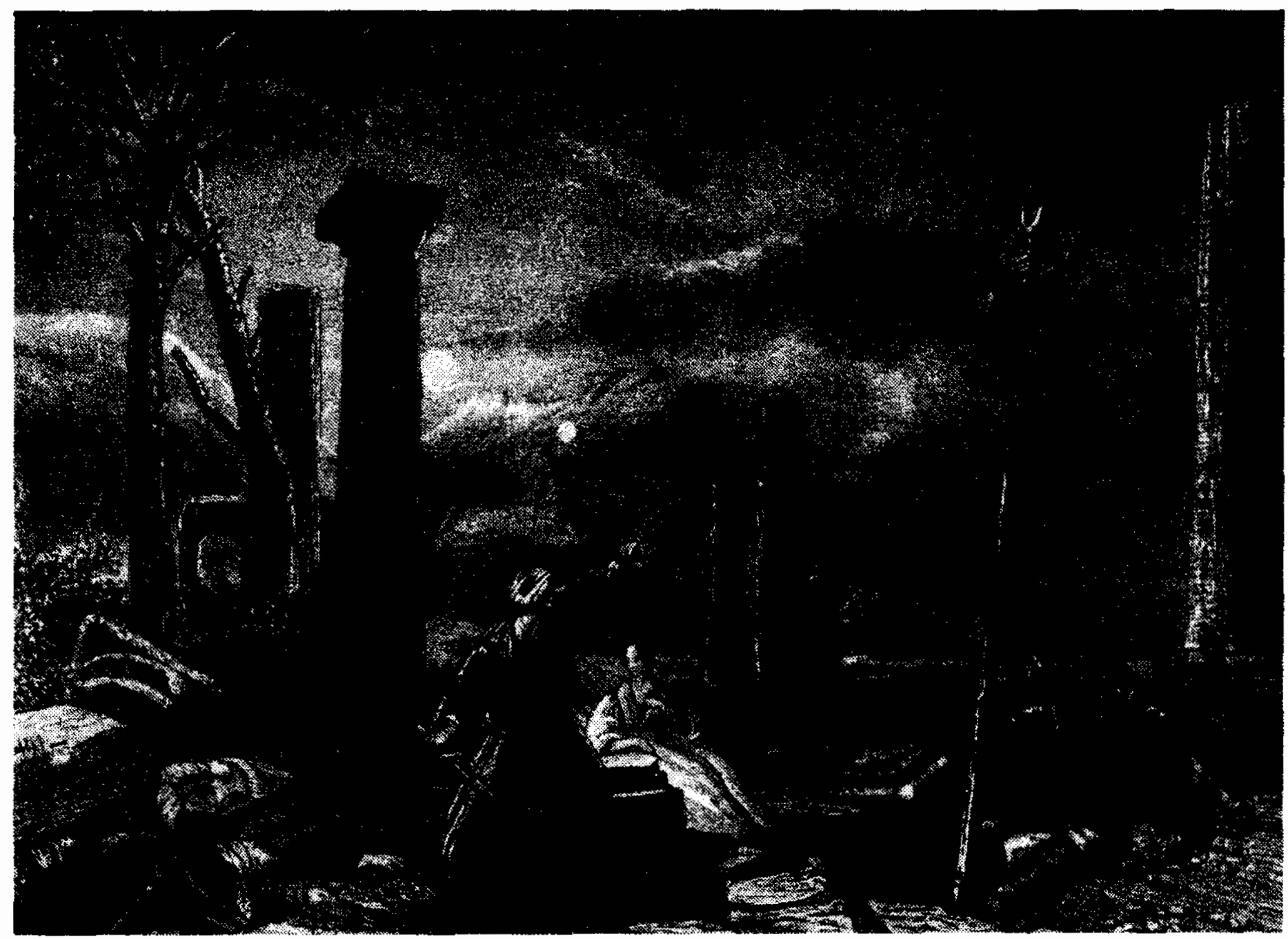

en alguno de los periódicos opositores. De vez en cuando algunos artículos hacían un frente común, como en el caso de la defensa de la colonia y la propuesta de una monarquía aparecidos en $E l$ Tiempo en 1846. El encarnizamiento en los debates aumentó hasta la irracionalidad en 1853; resulta extraño que este feroz conflicto de palabras se realizara en un ambiente de paz política y moderación. Los gobiernos de los generales Herrera y Arista, de 1848 a 1852, fueron tranquilos y los disturbios políticos se redujeron al mínimo. Esta calma era debida, en parte, a la postración del país y a la fatiga causadas por las continuas guerras y rivalidades. Las intenciones de Herrera eran honestas; fue el primer presidente, después de Guadalupe Victoria, en llevar a cabo su mandato y realizó varios esfuerzos para conducir al país a una situación de equilibrio. Limitó las fuerzas armadas, intentó iniciar un programa de moderación política y restauró la confianza del exterior en México. ${ }^{2}$ Pero esta moderación política, aunque necesaria, no fue posible después de 1847 , y para el año de 1852 el debate intelectual se transformó de nuevo en un conflicto político abierto.

\section{La posición liberal}

Después de la derrota, entre los círculos liberales se generalizó una actitud de desesperación acerca de la condición y

2 T.E. Cotner ha realizado un estudio de 12 administracion de Herrera, The military and political career of José Joaquin de Herrera, 1792-1854, Austin, 1949, pp. 173-301. 
el futuro de México. El periódico El Siglo $X I X$, en una de sus primeras publicaciones de la posguerra, cuestionaba con seriedad la condición del país:

Los elementos de desintegración acumulados en el país previamente [bajo la forma] de conflictos internos y recientemente extemos, han tomado ahora tal fuerza y son tan numerosos... que a primera vista uno podría dudar de si la república es realmente una sociedad o simplemente un grupo de hombres sin los lazos, derechos o deberes que constituyen a una sociedad. ${ }^{3}$

Nc era difícil evocar un sentimiento de desesperación en el México de 1848. La derrota frente a las tropas americanas fue sólo la culminación de una larga serie de rebeliones militares y de pronunciamientos cínicos que mantuvieron al país en una constante anarquía y que impidieron todo programa constructivo.

La apatía política reinaba y era la causa de la desesperación de muchos hombres patrióticos que trataban de vislumbrar una salida del caos. Mariano Otero reconoció esta apatía y se quejó de ella a José María Luis Mora en una carta escrita en 1848: "La apatía entre hombres respetables es peor que la actividad de los revolucionarios." Estos hombres, agregaba, constantemente se quejan del caos público, pero jamás levantan un dedo para remediarlo. ${ }^{4}$ El Monitor reconocía esta indiferencia política y la describía comouna "enfermedad social...mil veces

${ }^{3}$ El siglo $X I X, 1$ de junio de 1848.

4 Otero a Mora, 15 de septiembre, 1848, en Genaro García, (comp.), Documentos inéditos o muy raros para la bistoria de México, vol. VI, México, 1906, p. 113. peor que la anarquía misma".5 Siempre fue raro encontrar en México ciudadanos interesados en la vida pública y ahora frente a la calamidad había menos que nunca; de éstos, muchos eran hombres excepcionales, pero se enfrentaban a la tarea imposible de reconstrucción y organización. Desafortunadamente muchos de los que tenían cargos públicos eran aspirantes sin principios ni patriotismo.

De todas las regiones escribían hombres desesperados por el caos que los rodeaba. El joven Ignacio Ramírez, quien posteriormente tendría tanto poder como representante del liberalismo mexicano durante la época de Juárez, comenzó su carrera en 1846 editando una revista liberal satírica llamada Don Simplicio. A principios de 1846, incluso antes de comenzar la guerra, Ramírez se mostraba escéptico con respecto al futuro político del país. Por esos tiempos hubo una gran discusión política con respecto a un cambio de Constitución y las propuestas presentadas para un gobierno apropiado para México, que en opinión de Ramírez era inútil. "Hemos llegado-decía-al punto en que ya no se discute qué tipo de gobierno es mejor sino cuál puede mantenerse en México." $Y$ añadía cínicamente: "No hay motivo de preocupación, en realidad no deseamos el federalismo, ni el centralismo, ni la monarquía, solamente revoluciones. ${ }^{n 6}$ Los años de guerra y sus consecuencias produjeron un gran desaliento, y algunos llegaron a pensar que México ya no se levantaría; pero junto con el desaliento se producía una actitud de sobria refle-

' El Monitor Republicano, 3 de junio de 1847.

- Don Simplicio, periódico burlesco, critico y filosófico por unos simples, 14 de enero de 1846. 
xión acerca de la realidad mexicana y una sólida determinación de remediar los males que habían llevado al país a su estado actual.

Una prueba de la actitud reflexiva entre los pensadores liberales es un memorable panfleto de 56 páginas escrito anónimamente por varios mexicanos en diciembre de $1847 .{ }^{7}$ Hasta el momento este panfleto no ha recibido más que una atención tangencial por parte de los estudiosos de la historia de México, aunque en ocasiones aparece en las bibliografias y puede obtenerse en varias bibliotecas. El panfleto fue reimpreso en el popular El Monitor Republicano (13-24 de junio, 1848) con grandes elogios de los editores. Es un buen estudio detallado que se puede comparar favorablemente, a pesar de su brevedad, con los mejores escritos liberales de la época. El panfleto se refería al problema de la pronta derrota militar, e intentó analizar el motivo por el cual no hubo una resistencia nacional en 1847, algo similar quizá a la defensa popular en España contra Napoleón en 1808. Era una pregunta oportuna y su análisis condujo a una profunda discusión de los males básicos de México. Existen motivos, explica el autor, por los cuales "esta nación, lejos de tomar parte activa en la actual lucha, permanece como simple espectador desinteresado en el

7 Varios, Consideraciones sobre la situación politica y social de la Repriblica mexicana en el año 1847, México, 1848. Es posible que este excepcional panfleto haya sido escrito por Mariano Otero. La copia en la Colección Basave de la Biblioteca de México lleva escrito "Otero", posiblemente por el mismo Basave. Este meditado y crítico texto, así como la tentativa de paz y de reformas ciertamente sugieren a Otero. Tenemos la esperanza de que algún dia se establezca la identidad definitiva del autor. conflicto ${ }^{n} .{ }^{8} \mathrm{El}$ autor agregaba en seguida que esta indiferencia no provenía de defectos especiales o degeneración de la raza mexicana, como habían sostenido algunos extranjeros, sino que se trataba de aflicciones sociales que dejaban al país irremediablemente dividido.

El panfleto era un análisis que dividía en dos partes a la sociedad mexicana tal como la dividió José Ma. Luis Mora: la primera, formada por la población en general y los grupos productivos; la segunda, por los grupos privilegiados o clases improductivas. El autor describe la situación desesperada y lastimosa de los indígenas (el principal grupo de la "población en general"), y agregaba:

Es fácil entender la completa falta de interés de esta importante parte de la población de la república ya que por qué habría de preservar un sistema del cual es víctima. Sin duda los indígenas han contemplado la invasión norteamericana con la misma indiferencia con la que anteriormente observaron la invasión de las tropas españolas [...] ${ }^{9}$

No hay aquí ningún falso optimismo (como en algunos escritos liberales) acerca del mejoramiento de la condición de los indigenas a partir de la independencia, y de la obtención de su "ciudadanía", con derechos y responsabilidades individuales. De hecho, continúa el autor, tres cuartas partes de la población indigena probablemente no saben que México se ha independizado de España. Los tributos de la colonia (abolidos en 1821) aún se recaudan en muchas partes, y un cruel sistema de esclavitud y en-

\footnotetext{
- lbid, p. 4.

9 lbid., pp. 7-28.
} 
deudamiento mantiene a los trabajadores en las haciendas. Se han producido muy pocos cambios en la condición de los indigenas desde la época de Moctezuma. No ocupan un verdadero lugar en la sociedad. "Su única actividad en la vida pública de la nación es servir como soldados en el ejército y están obligados a ello por la fuerza." En suma, el autor sostenía que los indígenas eran meras "bestias de carga" y que aunque eran trabajadores y valientes era imposible pretender que defendieran a una "nación" que para ellos nada significaba.

El elemento "productivo" de la población, por supuesto el más importante según el autor, vivía en condiciones miserables y sólo alcanzaba a ser la cuarta parte del total. Esta proporción, decía, es tan pequeña que destruiría las posibilidades de progreso hasta de las naciones más favorecidas. Los grupos productivos son los del comercio, la agricultura, la minería, y las artes y oficios. El comercio es acosado por las altas tarifas, impuestos internos y las corruptas prácticas oficiales; además, agregaba el autor del panfleto, el gobierno ha insistidoen forzar el desarrollo industrial en detrimento del comercio y la prosperidad de la nación en general. El progreso de la agricultura es imposible ya que la Iglesia ha absorbidotres cuartas partes de las propiedades territoriales dejando al grupo productivo de pequeños agricultores como meros apéndices de la privilegiada institución. Este sistema de diezmos ha arruinado a los agricultores. La clase de los artesanos es tratada con desdén ya que se ha heredado la idea española de que las artes y oficios son ocupaciones bajas. Los mejores artesanos en cualquier categoría son extranjeros. Así, concluía el autor del panfleto, no había ningún motivo para esperar resistencia de parte de las "clases activas" en tiempos de la guerra.

Más tarde nuestro autor anónimo discute la otra parte de la sociedad mexicana: la de los grupos privilegiados o improductivos. En el transcurso de la discusión se cita tanto a Zavala como a Mora, y es obvio que el autor había sido influido por las incisivas críticas de estos últimos al clero, al ejército y a los empleados del gobierno. Como Mora, el. autor estaba muy impresionado por la enorme división de rangos dentro del clero, que dejaba empobrecido al bajo clero (un grupo muy valioso) mientras el arzobispo de México vivía con una cantidad que llegaba a los 50000 pesos al año por concepto de diezmos, lo mismo que otros altos oficiales. De esta forma, decía el autor, no hay unidad entre los miembros del clero, y cualquier cooperación para la defensa de la causa sería limitada. El alto clero abandonó la lucha en 1847 a pesar de sus fuertes intereses comprometidos.

Uno de los más escandalosos aspectos de la derrota mexicana de 1847 fue la escenificación de la absoluta descomposición del ejército, un grupo que constantemente había sido favorecido por el gobierno y que se mantuvo en extraordinaria desproporción. De acuerdo con el autor del panfleto los indígenas serían buenos soldados si fueran dirigidos por oficiales inteligentes. Desafortunadamente este último grupo se encontraba completamente degenerado. Las concesiones indiscriminadas de puestos militares es escandalosa, sostiene el autor, con el resultado de que muchos de los oficiales no saben nada del arte de la guerra. Así: "Cada nuevo gobierno, 
posible gracias a una revolución militar, ha creído que debe recompensar a quienes lo han llevado al poder. Estas compensaciones generalmente han consistido en otorgar trabajo inmediatamente a los oficiales."

Cada nueva revolución y su consiguiente gobierno están controlados por los militares que no ocuparon un lugar en el gobierno anterior. El autor afirma que no hay en el ejército lugar para un hombre honesto, ya que su carrera sería sofocada por los revolucionarios. El empleado burocrático, continuaba, es similar al oficial militar, a menudo es analfabeta, y mantiene su posición sólo gracias a su influencia y frecuentemente gasta de tres a cuatro veces lo que corresponde a su salario oficial. Es un descontento fuera de la oficina y siempre es bienvenido por la oposición política. ¿Cómo-pregunta el autor-pueden estos grupos poseer orgullo nacional y patriotismo y arriesgar su vida en defensa de México cuando sus empleos son escenarios de tanta corrupción?

Siguiendo la línea del pensamiento liberal de comienzos del siglo XIX, el autor del panfleto encuentra que la política española en la Nueva España y la sociedad colonial resultante explicarían la decadencia del país en $1847 .{ }^{10}$ Sin embargo el autor no encuentra grandes progresos en México a partir de la independencia. Considerando el carácter heterogéneo de la sociedad y los abusos crónicos que datan de la colonia, la indiferencia de los mexicanos con respecto a la guerra con Estados Unidos, dice, podría ser resumida de la siguiente forma:

${ }^{10}$ Ibid., Pp. 46-52.
"En México aquello que se ha dado en llamar espíritu nacional no existe ni ha existido, ya que no existe tampoco una nación. ${ }^{n 1}$ Esta fue una declaración intrépida en las condiciones de México, ya que a 25 años de independencia política, se negaba que el país pudiera ser llamado nación. Era comparable a la denuncia de Mora en 1833 del espintu de cueppo pero era aún más aguda dada la terrible crisis de diciembre de 1847.

Uno podría esperar que después de un recuento $\tan$ franco de la desintegración de la sociedad mexicana, se hicieran sugerencias que llevaran a una reforma radical; sin embargo éste no es el caso, ya que el autor se dedicó al análisis de la situación más que a dar soluciones. Las implicaciones eran fuertes ya que enfatizaba que debía tomarse la derrota como una lección y que era imposible que el país continuara con la misma línea después de 1848 que había mantenido hasta la fecha. Con esta declaración tan abierta y dramática de nuestra debilidad, dice el autor, nuestra vida nacional es cada día más precaria. De hecho, si las condiciones que nos han conducido hasta aquí persisten:

Entonces será absolutamente necesario que cualquier mexicano consciente de tener algo que perder, deberá convencerse de la verdad, [...] de que no podemos continuar solos como nación, y que necesitaremos, por lo menos durante unosaños, de la intervención armada de un poder extranjero. ${ }^{12}$

"lbid., p. 42. Esta declaración está escrita con mayúsculas en el texto original.

${ }^{12}$ lbid, p. 56. 


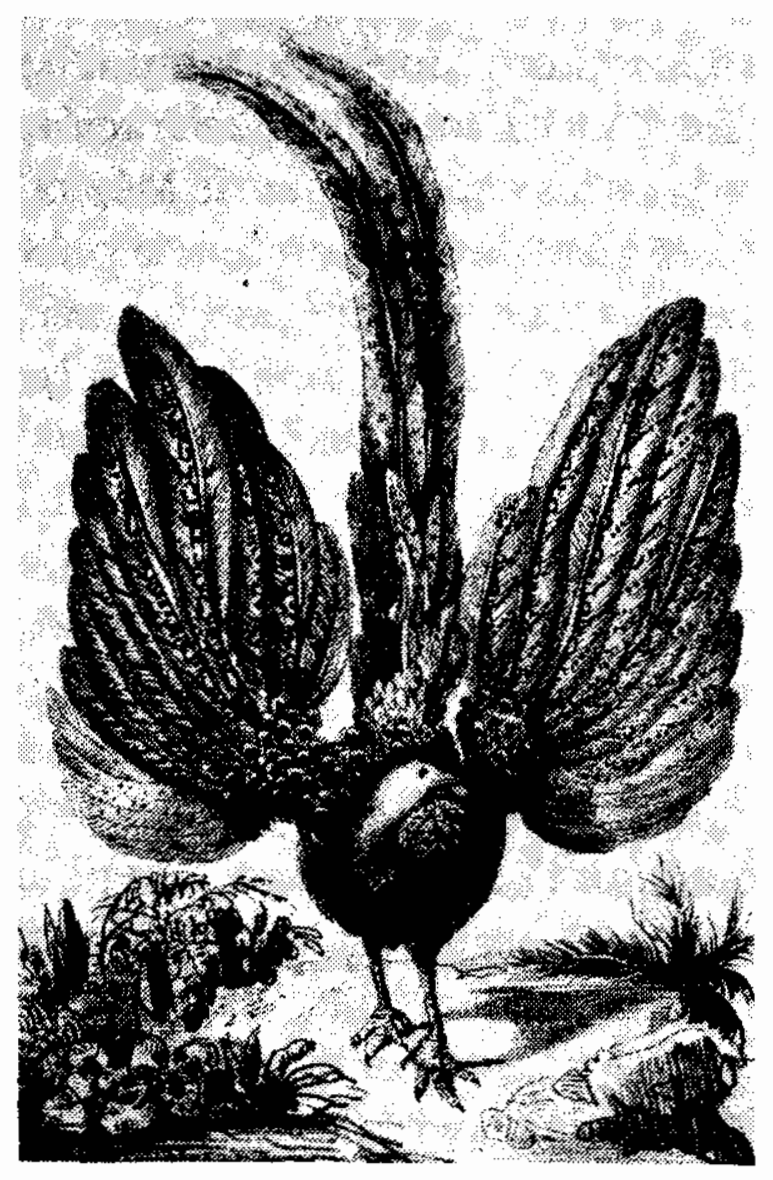

Lo único que queda por resolver, entonces, es si será Estados Unidos o alguna monarquía europea quien intervenga. El autor concluye esperando que México tenga la sensatez suficiente para evitar ambos extremos. Los mexicanos liberales veían la asimilación por parte de Estados Unidos como una verdadera amenaza. ${ }^{13}$ Escribía Otero al Dr. Mora en 1848 acerca de la existencia de dos partidos opositores que "defienden la misma idea: la de nuestra incapacidad de gobernarnos a nosotros mismos". ${ }^{14}$ Otero expresaba el constante temor de que alguno de los partidos, ya fuera el que clamaba

${ }^{13}$ Véase M.C. Rejón, Obsenuaciones del diputado saliente...contra los tratados de paz..., Querétaro, 1848, p. 35.

14 Cara del 14 de octubre de 1818, G. García (comp.), op. cil., p. 121. por una monarquía extranjera o el que proponía la anexión a Estados Unidos, comenzaran a actuar en favor de sus objetivos. La independencia mexicana se encontraba claramente amenazada y el país debería tomar un nuevo curso o perecer.

El deseo de reforma que había surgido en México a partir de la crisis provocada por la derrota militar, no podía convertirse en una fuerza activa inmediata; el partido liberal había emergido de la guerra dividido. Los moderados se opusieron al intento del gobierno de Gómez Farías, en enero de 1847, de reunir 15000000 de pesos hipotecando o vendiendo en una subasta pública los bienes de manos muertas (la mayoría del clero). El ala radical del partido liberal no veía con buenos ojos la paz negociada de 1848 y posteriormente se refería a ella como "la criatura de los moderados". 15 Los gobiernos que siguieron a la posguerra fueron dominados por los moderados hasta el retorno de Santa Anna en abril de 1853; pero no fueron totalmente exitosos ya que carecían del apoyo de los puros o del ala radical. Existe poca duda de que todos los liberales, tanto moderados como radicales, vieran la necesidad de una reforma general para que México se levantara de su postrada condición. Ambas facciones hablaban y escribían sobre la reforma, perocualquier acción siempre quedaba obstaculizada por la desunión entre ellas. No fue sino hasta que triunfó el enemigo común en 1853 cuando los liberales cerraron filas y en 1854 pudieron presentar un programa de reforma más sólido.

15 Vicente Riva Palacio (comp), México a través de los siglos, vol. Iv, Barcelona, 1888, p. 718. 
Los escritos de la época hacen un llamado constante a la unidad entre los liberales. Si la nación misma se había desintegrado en 1847 , la unión de los liberales fue el primer paso para la integración; así, apelaba El Monitor. "Todos los hombres del partido liberal deben unirse sinceramente y sin pérdida de tiempo establecer un solo partido nacional. ${ }^{n 6}$ Para 1851 las líneas se habían definido más claramente al enfrentar la presión de los conservadores, y el mismo periódico afirmaba: "en nuestra opinión sólo existen dos partidos en la república: el conservador y el liberal". ${ }^{17}$ Las dos facciones del partido republicano, continuaba, concuerdan en el fin por el cual están trabajando, ahora deben concordar encuanto a los medios. Melchor Ocampo, un joven y franco liberal de Michoacán, vio claramente la necesidad de una unidad de partido, pero también comprendió que no se trataba de una tarea fácil. ${ }^{18}$

Los años posteriores a la guerra con Estados Unidos fueron testigos del surgimiento de una nueva generación de pensadores y estadistas liberales distinguidos. El liberalismo se había debilitado en la década posterior a la caída del gobierno de Gómez Farías en 1834, y pocos asumieron los puestos de los anteriores partidarios de la reforma. Existe poca evidencia escrita de un pensamiento liberal serio en la década anterior a la guerra. El doctor Mora abandonó México 1849

16 El Monitor Republicano, 24 de junio de

${ }^{17} \mathrm{Jbid}, 18$ de junio de 1859.

"Véase Melchor Ocampo, carta a D.A. García, 8 de marzo de 1853, Obras completas, vol. II, México, 1901, p. 291. en 1834, y dejó de lado su participación en los asuntos mexicanos, aunque sus escritos ejercieron considerable influencia, lo mismo que su labor como embajador en Inglaterra desde 1846 hasta su muerte en 1850 . Lorenzo de Zavala salió de la escena en 1834 y murió en Texas dos años después. Miguel Ramos Arizpe se retiró de la política en 1833 y pasó una vida tranquila en Puebla la década siguiente. Andrés Quintana Roo murió en 1851, y pasó sus últimos años alejado de la vida pública. Elúnico miembro de la vieja generación de liberales que perduró fue Valentín Gómez Farías, que trató de organizar un gobierno liberal en 1846 y jugó un importante papel en las negociaciones de paz. Posteriormente se retiró.

Una nueva generación ocupó su lugar. Melchor Ocampo, ya miembro distinguido de la Asamblea Constituyente de 1842 y gobernador de Michoacán en 1846 , fue el líder intelectual; Benito Juárez era gobernador de Oaxaca, y había instituido reformas liberales que presagiaban su futuro papel como líder político de la "gran reforma"; Guillermo Prieto, un joven poeta, economista y estadista escribía ya en 1847 , al igual que Ignacio Ramírez; Mariano Otero hubiera podido ser un resuelto miembro de la nueva banda de liberales de no haber muerto prematuramente en 1850. Algunos otros dentro de este grupo que habrían de ganar importancia como pensadores y estadistas después de 1853 eran FranciscoZarco, Ponciano Arriaga, José María Mata, Santos Degollado, etcétera. La crisis de 1847 afectó a estos hombres, obligándolos a reconsiderar la condición presente y futura de México y a aguzar sus convicciones, que serían las bases 
para la acción durante la gran reforma de 1857.

\section{Los voceros de la reforma}

Quizá el principal vocero de la reforma durante el tiempo que siguió a la derrota fue Melchor Ocampo. Su nombre hizo ecoen Méxicoen 1851 cuando "el párroco de Maravatío" (el doctor don Agustín Dueñas) publicó una réplica a la recomendación de reformar las cuotas parroquiales presentada por el gobernador Ocampo al Congreso del estado de Michoacán. Las cuotas parroquiales impuestas al pueblo por los clérigos de las provincias como su único medio de obtener ingresos, habían sido frecuentemente atacadas por José Ma. Luis Mora, Lorenzo de Zavala y otros liberales en 1833; pero durante la década siguiente la opinión liberal permaneció en silencio y nada se hizo para cambiar esos abusos; ahora Ocampo demandaba una reforma en estas cuotas, reguladas legalmente por la diócesis de Michoacán desde 1731. ${ }^{19}$ Las cuotas eran exorbitantes y se evadian cuando era posible. Las elevadas cuotas para el matrimonio eran una de las causas principales de la ilegitimidad. Los entierros se llevaban a cabo al capricho de los clérigos y con un costo extraordinario para el parroquiano pobre. El párroco de Maravatío tomó como propia la tarea de contestar a este ataque a los privilegios de la Iglesia y se abrió un polémico debate en el cual Ocampo

19 "Representación sobre la reforma de aranceles $y$ obvenciones parroquiales...", en Ocampo, La repuiblica, la Iglesia y el clero, México, 1948, p. 21 . escribió cinco ensayos distintos en los que elaboró su original petición de reforma.

Con la publicación de sus ataques a los impuestos y cuotas parroquiales, Melchor Ocampo se convirtió en el líder del anticlericalismoen México. Todas sus "réplicas" al párroco de Maravatío fueron reimpresas por El Monitor Republicano, y se incitó a los editores del periódico a comenzar su propia campaña de reforma. Ocampo argumentaba que las cuotas que se exigían eran básicamente para funciones civiles, así como bautismos, matrimonios y entierros, y que el gobierno debía controlar la colecta de cuotas como lo hacía el rey en el siglo xvIII. Declaraba que cualquier pago que se hiciera a la Iglesia por parte de los mexicanos pobres para estas ceremonias básicas debería ser voluntario; a pesar de atacar estos abusos, Ocampo declaró prudentemente que la mayoría de los clérigos de las parroquias eran hombres de conducta ejemplar y que antes morirían de hambre que tomar para sí el dinero de los fieles. Juan Portugal, el anterior obispo de Michoacán, fue un guía ilustrado que logró muchos cambios en cuanto a la conducta de sus párro$\cos ;{ }^{20}$ pero el sistema era ya demasiado malo, necesitaba una reforma, y Melchor Ocampo habría de dedicar sus mejores años a esta tarea.

El Monitor difundió la nueva demanda de reforma en otras áreas bien conocidas, como los bienes de manos muertas de la Iglesia y los privilegios del clero. Lo que más enfurecía a los editores de $E l$ Monitor era que la Iglesia no tomara

${ }^{20}$ Ibid., p. 32. 
parte en el conflicto con Estados Unidos, ya fuera moral o materialmente, y que incluso promoviera una revuelta contra el gobierno en la capital cuando se turnó la ley acerca de las propiedades de la Iglesia en enero de $1847 .^{21}$

Día a día durante todo el año de 1851 los editores de $E l$ Monitor atacaron el problema de la reforma del clero. Artículos aislados y algunos en serie se consagraron a la libertad de cultos, los diezmos, los privilegios del clero en las cortes, la necesidad de un registro civil y los demás principios del programa liberal. El Siglo $X D X$ favorecía más al gobierno de Herrera que respetaba fielmente a la Iglesia, sin embargo, por lo general, los liberales se comprometieron con una reforma radical de la Iglesia como un primer paso para salvaguardar a la nación de una ulterior desgracia.

Al enfrentarse a los conservadores que atacaban el propio centro de la existencia de un México independiente y al sondear los asuntos fundamentales de la nación, entre 1847 y 1853 hubouna fuerte reafirmación de los liberales respecto a las instituciones republicanas de México. Era fácil para los conservadores cuestionar la validez de los principios republicanos puesto que habían ocasionado 30 años de caos político, coronados con una invasión humillante y la consecuente pérdida del territorio. Como Otero señaló a José Ma. Luis Mora, las ideas monárquicas habían logrado grandes avances en el país después de la guerra y el recién formado partido conservador era un elemento bastante temible. ${ }^{22}$ Los liberales

${ }^{21}$ El Monitor Republicano, 6 de julio de 1851.

22 Otero a Mora, 13 de mayo de 1849, García (comp.), op. cit., p. 140. comprendieron esta amenaza y con diligencia contestaron los ataques conservadores a Hidalgo, al federalismo, y a la república en general, así como a las insidiosas evocaciones de la paz y la prosperidad de la colonia. Para el año de 1853 la validez de los principios republicanos en México se convirtió en la esencia del gran debate entre los grupos en conflicto.

Los liberales por logeneral menospreciaban las ideas monárquicas y declaraban que la sociedad mexicana era básicamente de carácter republicano y que nunca aceptaría libremente de nuevo la monarquía. Encontramos este sentimiento perfectamente expresadoen un panfleto de autor anónimo:

La mayor parte de la vigorosa generación actual nació durante la revolución, y el pasado [coloniall pintado con tanta magnificencia [por el periódico El Tiempo] es algo ajeno a ella. El odio por el opresor llenó sus primeros días y las ilusiones de la libertad y de una república los arrullaron en sus cunas. Estos hombres no se resignarian facilmente al yugo. ${ }^{23}$

El Monitor declaraba que el partido conservador ganaba muy pocos prosélitos, que dejando de lado a unos pocos hombres educados en la época colonial, sólo unos cuantos jóvenes descarriados aceptaban su ridículo anacronismo. ${ }^{24} \mathrm{El}$ destino de México era republicano, afirmaban los liberales. Pensaban que no había motivos por los cuales el país no pudiera aceptar el desafio de las instituciones republicanas y ganar la paz y la estabilidad política; sin embargo, los

23 La política de las editores de El Tiempo analizada ante la nación, México, 1846, p. 14.

2430 de abril de 1848 . 
ataques de los conservadores eran devastadores, ya que golpeaban los puntos más débiles de la república: la continua anarquía y confusión políticas. Los liberales se habían encolerizado por las insinuaciones de que México se encontraba mejor como colonia que como país independiente y acusaron a los conservadores de ser agentes de un nuevo colonialismo. Ahora los liberales se veían forzados a comprender que no todo había sido felicidad desde 1821 y que la consolidación política era imperiosa.

\section{La posición conservadora}

Si la derrota militar hizo evidente a los liberales la decadencia de la nación, el hecho fue aún más obvio para los conservadores, quienes habían sostenido todo el tiempo que la trayectoria del México independiente estaba equivocada. Tanto conservadores como liberales escribieron poco entre 1834 y 1846. Fueron excepciones el panfleto de José María Gutiérrez Estrada, ${ }^{25}$ una obra ocasional de Alamán y los escritos económicos de Esteban de Antuñano (si se le puede considerar conservador). Pero al enfrentarse con la guerra y la derrota, los conservadores mexicanos reavivaron su intensa crítica a las instituciones republicanas y reafirmaron su programa para salvar a la nación.

Gutiérrez Estrada, en una carta enviada a Roma en 1848 , decía que la derrota era el resultado de 25 años de "complicidad en el desorden y la confusión", y acusaba a la nación por su incorregi-

${ }^{25}$ Infra. bilidad ${ }^{26}$ Cuando Lucas Alamán se sentó a escribir la introducción del primer volumen de su Historia de Méfico, se cuestionaba sinceramente si México existía aún como nación. Sugería que su historia podría ser de utilidad de cualquier forma; podría lograr que futuras generaciones de mexicanos fueran más cautelosas a la luz de la debilitante anarquía de la República mexicana y a la calamitosa derrota de 1847; o tal vez podría servir para instruir a otros países latinoamericanos con la lección de México, que habría sucumbido a la dominación extranjera (probablemente yanqui). La guerra tenía una gran importancia para Luis $G$. Cuevas que veía "el peligro en el cual [Méxicol se encontraba de perder su nacionalidad e independencia ${ }^{n}$, y que decidió escribir su Ponvenir de México en 1851 ya que con "una sociedad desunida, rotos todos los lazos del orden y bienestar público, se hace necesario un examen minucioso... ${ }^{n 27}$ Las bases del carácter mexicano y su desarrollo debían ser investigados, más aún, ahora que México necesitaba una afirmación de sus principios que podría salvar al país del amenazante desastre.

La voz de Lucas Alamán era la que más fuerza daba a las declaraciones de los conservadores; uno de los objetivos principales de los escritos históricos de Alamán fue cambiar la tendencia hacia el liberalismo que había en el siglo xIx, y que negaba la herencia española del México independiente. Alamán presentó

26 Gutiérrez Estrada, México en 1840 y en 1847, México, 1848, p. 17.

${ }^{27}$ Luis G. Cuevas, Ponvenir de México, o juicio crítico sobre su estado político en 1821 y 1851, México, 1851-1857, p. x. 
claramente este objetivo en una carta al duque de Terranova y Monteleone el 3 de diciembre de 1851:

Me pregunta usted el efecto en la opinión pública de mi Historia de Méjico y mis Disertaciones. Han alterado completamente las ideas sostenidas por la fuerza en las declaraciones revolucionarias sobre la conquista, la dominación española y la forma en que se llevó a cabo la independencia. Se creía que la conquista era un robo [...] y la dominación española una continua opresión [...]; todo esto ha cambiado radicalmente. A uno le basta con ver algunos de los discursos de este año en donde la conquista se representa como el establecimiento de la civilización y la religión; a Cortés como un hombre extraordinario al que la Providencia destinó a llevar a cabo estos objetivos y a la dominación española como un gobierno moderno y benévolo que preparó al país para la independencia y la organizó en todas sus áreas. ${ }^{28}$

También fue de importancia vital para la misión de Alamán el intento de cambiar la concepción popular de la revolución de Independencia, que exaltaba a Hidalgo y menospreciaba a Iturbide. Iturbide era el héroe de Alamán, e Hidalgo debía ser despreciado. Alamán consideró que su apelación había tenido un gran efecto y no se equivocaba ya que las ideas conservadoras se habían hecho más populares después de 1847. Como los liberales se vieron forzados a una mayor militancia, México se vio dividido por el debate acerca de los principios básicos.

Como parte de este gran debate que surgió después de la guerra de 1847, los

26 Alamán, Documentos diuersos, vol. Iv, México, 1945-47, p. 604; también en el vol. xal de sus Obras. conservadores comenzaron una campaña contra el liberalismo, la democracia, el federalismo y la reforma, tal como se habían aplicado en el México independiente. Alamán se unió a esta campaña por medio de sus escritos pero fueron los periódicos los que presentaron las mayores críticas a las instituciones republicanas. Al refutar a $E l$ Siglo $X D X, E l$ Universal decía:

El ideal que representa El Siglo, el ideal democrático, es uno que se rechaza por los hábitos, las costumbres, lastradiciones, las inclinaciones, los deseos y las necesidades de las razas que constituyen nuestra sociedad. ¿Dónde están los antecedentes democráticos en la raza azteca?...¿En la española? El ideal democrático no tiene en nuestro país raison d'être. ${ }^{29}$

La democracia entonces es algo que se impone a México, continuaba el editor, donde permanecen los principios de la monarquía, el catolicismo y el respeto a la autoridad. El Tiempo, tratando de desacreditar el liberalismo, citaba largamente la Memoria de Zavala de 1833 para demostrar que aun él era escéptico en cuanto a la democracia y que creía impráctico instituirla en México. ${ }^{30}$ En 1852 El Orden se lanzó al ataque del principio del federalismo que, según sostenía este periódico, había fracasadoen México por la heterogeneidad de su población. Afirmaba $E l$ Orden que una cosa era establecer el federalismo en Estados Unidos, donde la unidad e ilustración de la sociedad posibilitaban esta avanzada idea, y otra establecerloen México donde causaba grandes desórdenes. El fracaso

${ }^{29}$ El Universal, 22 de julio de 1853.

${ }^{30}$ El Tiempo, 15 de febrero de 1846. 
de la resistencia al invasor norteamericano se atribuía en gran medida a esta "doctrina trastornante". ${ }^{31}$

Durante los años posteriores a la invasión hubo una manifestación clara de los principios conservadores positivos; algunos habían aparecido anteriormente pero ahora se formulaba un programa fuerte y más elaborado. En la base del programa conservador se encontraba el respeto por la tradición. Sin duda, los principios conservadores basados en la tradición triunfarán, afirmaba El Untversal, pues se encuentran firmemente enraizados en los corazones y mentes de los mexicanos: "Los principios religiosos, de la propiedad privada, de la familia y de la moralidad" nunca cederán ante las ideas anárquicas e irreligiosas de la democracia y el federalismo. ${ }^{32}$ La libertad es en verdad una meta admirable pero sólg si se combina con el orden, sin éste la libertad no tiene sentido. ElOrden creía que estos dos principios se habían reconciliado durante la época colonial e insinuaba que lo mismo sucedió con el benevolente dictador Santa Anna en $1853 .{ }^{33}$ Por último, los conservadores defendian una legislación que se mantuviera en armonía con la sociedad. México debía ser realista al contemplar las potencialidades de su sociedad, decía El Universal, de otra forma las leyes no serían obedecidas. ${ }^{34}$

El respeto por la Iglesia en todas las esferas ocupaba un lugar principal en el

${ }^{31}$ El Orden, 25 de agosto de 1852; 11 de marzo de 1853. Vése también, Algunos mexicanos, Manifiesto a la nación, s.p.i., (1851?) p. 4.

${ }^{2}$ El Universal, 1 de noviembre de 1853.

${ }^{33}$ El Orden, 27 de agosto de 1853.

${ }^{34}$ El Universal, 22 de noviembre de 1848. programa conservador. No se hacía ninguna diferencia entre el "principio religioso" y la Iglesia triunfante, poseedora de la mitad de las riquezas del México independiente. Alamán admiraba la estabilidad de la Iglesia e insinuaba que no se le debía atacar: "En medio del caos de los elementos de nuestra sociedad lo único que se ha mantenido inmutable ha sido la Iglesia. ${ }^{\text {"35 }}$ El Monttordeclaraba en 1848 que confiaba en que la gente rechazaría el ataque liberal contra el clero y agregaba que "el sagrado ministerio no puede mantener su dignidad e independencia sin sus propios fondos, administrados y distribuidos por sí mismo". ${ }^{36}$

Los conservadores incitaban a menudo al país a revisar los antecedentes del gobierno de Anastasio Bustamante (1830-1832), en donde se habían instituido los genuinos principios conservadores; en una atmósfera ordenada la Iglesia había recuperado su dignidad y se asignaron buenas autoridades. Por medio de un control centralista (aunque se mantenía el federalismo en teoría) había mejoras en materia económica. Se podrían cobrar impuestos y de esta forma rehacer el tesoro nacional; el dinero no se disiparía en las provincias. El Universal veía con agrado el año de 1830 cuando "[el gobierno] estimulaba todas las ramas de las riquezas y prosperidad nacionales. En suma, ésta fue la mejor época para los mexicanos desde la independencia. ${ }^{\text {n37 }}$

Después de la guerra con Estados Unidos, Alamán buscó una nueva opor-

"Alamán, Historia de Méjico, vol. v, México, 1849-1852, p. 906.

${ }^{36}$ El Universal, 13 de julio de 1849.

${ }^{37}$ lbid., 2 de agosto de 1849. 
tunidad para llevar a cabo su filosofia conservadora. Las rebeliones eclesiásticas y militares contra los gobiernos liberales en Michoacán le dieron la oportunidad, ya que la revuelta conservadora se extendió inmediatamente a la capital. Alamán y sus camaradas conservadores se inclinaron (quizá con ciertas reservas) hacia Santa Anna y esperaron que el general constituyera un frente unido para establecer su régimen conservador. Previendo la posibilidad de que Santa Anna se independizara y volviera a sus extravagantes tendencias dictatoriales, Lucas Alamán le dirigió al general en el exilio en Sudamérica la ahora famosa carta con su acostumbrada agudeza y estilo. ${ }^{38}$ En ella Alamán declaraba los principios del partido conservador y le hacía ver a Santa Anna que si deseaba permanecer en el poder habría de seguirlos. El más importante de éstos era "el conservar la religión católica...como el único lazo que une a los mexicanos cuando todos los demás se han roton. Esto significaba, por supuesto, respeto a las propiedades de la Iglesia y buenas relaciones con el papado. Alamán concluía señalando que debería fortalecerse el ejército y que era imperativa la existencia de un gobierno firme.

Sellamó a Santa Anna de nuevo, quien se convirtió en presidente del gobierno conservador con Alamán como ministro de Relaciones Exteriores. Pero Alamán murió el 2 de junio de 1853 y con ello

34 La carta estŕ fechada el 23 de marzo; le fue entregada a Santa Anna por Antonio Haro y Tamariz, posteriormente ministro. El texto integro se encuentra en Francisco de Paula Arrangoiz, México desde 1808 basta 1867, vol. II, Madrid, 1872, pp. 335-340. cualquier esperanza de controlar a Santa Anna. El general se convirtió en amo e instituyó su propia interpretación de los "principios conservadores"; se nombró a sí mismo "emperador" con numerosos títulos y resucitó el oropel y la ostentación del imperio de Iturbide. El sueño de conservadurismo de don Lucas Alamán se volvió ridículo y sus colegas se inclinaron hacia programas más reaccionarios. ${ }^{39}$

Uno de los aspectos que acaparó la prensa durante el gran debate de 1846-1853 fue una cuestión de interpretación histórica acerca del día que podía considerarse el de la independencia. Este debate surgió al cuestionar los conservadores la contribución de Hidalgo a la independencia y proponer en su lugar a Agustín de Iturbide como héroe nacional. El principal exponente de esta interpretación era Alamán, pero hubo otros que exaltaron a Iturbide por su campaña para desacreditar el México republicano. Su nombre era regularmente mencionado por todos los periodicos conservadores y se desarrolló una gran nostalgia por el triunfante y conservador Plan de Iguala.

Luis G. Cuevas, el anterior ministro de Relaciones Exteriores, publicó un libro en 1851 en el que intentaba comparar la condición de México en 1821 con las perspectivas de su propio tiempo y describir los sucesos intermedios. ${ }^{40}$ Nunca completó su cometido, pero presentó un recuento de la revuelta de Iturbide y la condición del país en 1821, dejando claras al lector las implicaciones que suscitaron

39 Para una visión conservadora de las relaciones con Santa Anna, vease El partido conservador en México, México, 1855.

${ }^{10}$ Cuevas, op.cit. 
la comparación. En 1821 el panorama era favorable: "Al separarse de la madre patria, pareció que México tenía potentes elementos para figurar en el mundo y llamar la atención de la gente civilizada, por su clima, territorio, situación geográfica y supremacía entre los estados latinoamericanos. ${ }^{n 11}$

Se hacía mal en afirmar que los problemas actuales se originaron en 1821 , decía el autor, ya que la paz, el orden y la unidad se dieron con el Plan de Iguala. La astuta política conservadora, que fue el principio más importante de Iturbide -a saber, la unión entre españoles y mexicanos-, dio a México grandes esperanzas de progreso y estabilidad futuros. Al negar los liberales su herencia española y perseguir a los españoles se dio paso a la anarquía. Alamán afirmaba, en sus escritos de 1852, que Iturbide fue muy inteligente al defender una monarquía moderada en el artículo $3^{\circ}$ del Plan de Iguala, ya que en un país tan heterogéneo socialmente como México el gobierno no debe romper abruptamente con el pasado. ${ }^{42}$

\section{La monarquía como solución}

Durante los 30 años que siguieron a la independencia los conservadores se desalentaron cada vez más con los gobiernos republicanos y empezaron a buscar medidas extremas para resolver los males de México. Al principio trataron de ser buenos republicanos, pero al atacar los liberales del ala radical sus estimadas tradiciones $\mathrm{e}$ instituciones $\mathrm{y}$

${ }^{1}$ Ibid., p. 2.

${ }^{42}$ Alamán, listoria, vol. v, p. 110. apoderarse del país la anarquía política, perdieron la fe en el México republicano. En 1840, José María Gutiérrez Estrada, después de presenciar con disgusto las revoluciones y contrarrevoluciones de ese año -descritas brillantemente por madame Calderón de la Barca-, escribió la "famosa" carta al presidente Bustamante que conmocionó al país. ${ }^{43}$ La carta fue la primera enunciación abierta de una idea que pronto se convirtió en el principio político básico de los conservadores: la necesidad de la monarquía en México; fue tan mal acogida que Gutiérrez Estrada tuvo que escapar a Europa y el editor Ignacio Cumplido fue encarcelado. ${ }^{44}$ Madame Calderón de la Barca apunta que el panfleto "parece que puede causar un revuelo mayor que el complot de la pólvora en Inglaterra ${ }^{n} .{ }^{15}$ El Mosquito Mextcano se refiere al asunto como el único del momento.

Gutiérrez Estrada presentó su propuesta a Bustamante después de una "prolongada y penosa...lucha entre mi razón y mi puro y sincero corazón republicano". ${ }^{46}$ Hemos mirado hacia Estados Unidos, escribió, y concluí que sus instituciones deben también ser nuestras pero nuestras tradiciones y nuestro pasado no son republicanos, como los

4 Carta dirigida al excelentismo señor presidente de la repuiblica sobre la necesidad de buscar en una convención el posible remedio de los males que aquejan a la repuiblica y opiniones del autor acerca del mismo asunto, México, 1840.

14 Véase I. Cumplido, Manifiesto al público del impresor...con motivo de su prisión..., México, 1840.

4" Calderón de la Barca, Life in Mexico, Nueva York, 1913, p. 271.

${ }^{46}$ Carta..., p. 84. 
de Estados Unidos. Todas sus leyes, sus costumbres, sus virtudes y hasta sus vicios fueron republicanos, asi que la proclamación de independencia fue tan sólo cuestión de transferir el poder político del rey al presidente. ${ }^{47} \mathrm{El}$ republicanismo en México, al contrario de la experiencia de nuestro vecino, sólo ha traído la opresión y la anarquía alternadas. Gutiérrez Estrada sostuvo con fuerza su punto principal: "La triste experiencia de lo que este sistema [republicano] ha sido para nosotros, parece autorizarnos ahora a hacer en nuestro país un intento de monarquía auténtica en la persona de un príncipe extranjero." Pero, continúa, esto no significa que soy partidario del despotismo o agente de algún gobierno extranjero. 48 "Todo en México es monárquico", y una monarquía constitucional garantizará más libertad y con seguridad más paz que la república más ilustrada. Ya en 1840 Estrada preveía la amenaza de Estados Unidos y empujaba a México a establecer un gobierno firme sobre principios monárquicos, si no "quizá no pasarán veinte años antes de que veamos las barras y las estrellas ondear sobre nuestro Palacio Nacional... . ${ }^{49}$ ¡Proféticas palabras!

Bajo la amenaza de una inminente invasión norteamericana, los conservadores publicaron durante la primera mitad de 1846 su periódico más valiente, $E l$ Tiempo, que se supone fue inspiración de don Lucas Alamán, quien tuvo in-

47 lbid., p. 47.

4 Ibid., p. 37.

49 lbid., p. 58. clinación por la monarquía cuando era joven, pero había abrazado la república con entusiasmo ${ }^{50} \mathrm{y}$ desempeñó un papel importante en la política de 1820 a 1830 ; en este último año su ministerio se basó en principios republicanos pero, como Gutiérrez Estrada, se desilusionó, y con una guerra amenazando la independencia de México volvió sus ojos a la monarquía. ${ }^{51}$ Más tarde se convirtió en el principal colaborador de El Universal (aunque no se han determinado los artículos que son suyos). Alamán mostró cierta inclinación por la monarquía en su Historia de Méjico, escrita entre 1849 y 1852 , pero faltaba una defensa abierta del principio. Es probable que Alamán viera ya en 1853 que había pocas esperanzas inmediatas del establecimiento de una monarquía, así que dio su apoyo al candidato de compromiso dudoso, Santa Anna. Arnaizy Freg sugiere, sin embargo, que Alamán habría servido como ministro de Relaciones Exteriores de Maximiliano, y es probable que tenga razón. ${ }^{52}$ Tampoco debemos dejarnos llevar por los patriotas liberales que llaman traidor a Alamán, pues debe recordarse que su principal llamado a México era la con-

\footnotetext{
${ }^{50}$ Véase la refutación de Alamán a la acusación de Tornel de que él había sido un monárquico desde su juventud, Alamán, Historia, vol. v, p. 807.

"Lo hizo, si podemos asumir que él era el editorialista de $E l$ Tiempo; pocas fuentes contemporáneas lo niegan y muchos escritores de ambos bandos lo señalan como la cabeza del partido monárquico. Jorge Gurría Lacroix presenta un Alamán que está lejos de ser un monárquico toda su vida, pero este planteamiento no puede documentarse (Las ideas monárquicas de don lucas Alamán, México, 1951). Véase también Moisés González Navarro, El pensamiento politico de Lucas Alamän, México, 1952, pp. 122-126.

52 El Tiempo, 14 de marzo de 1846.
} 
servación de su herencia española y no la aceptación de un príncipe extranjero.

El Tiempo esperaba que quizás Paredes de Arrillaga, que había llegado a la presidencia mediante la rebelión militar de diciembre de 1845, llamaría a un príncipe extranjero para ayudar a México en esta desesperada situación. El periódico salió del 24 de enero al 7 de junio de 1846, cuando dejó de publicarse como protesta contra la decisión final de Paredes por la forma republicana de gobierno. Durante esos meses El Tiempo mostró la situación deteriorada del país frente a la invasión y, después de algunos aguijonazos de los periódicos liberales, presentó una apasionada súplica para el establecimiento de una monarquía constitucional: "Todos los mexicanos están de acuerdo en que las dificultades del país han llegado a tales extremos que si la Providencia no nos envía un remedio efectivo, la ruina es segura. ${ }^{n 53}$ Un gobierno fuerte y enérgico es la única solución; México "tendría que vivir bajo un gobierno fuerte que pueda hacerlo respetable o desaparecerá para siempre del catálogo de las naciones" ${ }^{54}$ El 12 de febrero de 1846 El Tiempo hizo su "profesión de $\mathrm{fe}{ }^{.55}$ Afirmaba el autor: "Queremos una monarquía representativa; queremos la unidad de la nación, libertad política y civil, las garantías del Plan de Iguala y una aristocracia de mérito." La "jerarquía militar" debía ser

"I Ibid, 29 de enero de 1846 .

34 Arturo Arnaiz y Freg, "Prólogo" a Lucas Alamán, Semblanzas e ideario, México, 1939, p. xxxIII.

"Esta famosa declaración fue probablemente escrita por Alamán, véase González Navarro, op. cit., p. 124. respetada, como debía serlo la religión católica en todo su esplendor, y el clero debía dejarse en paz. El artículo continuaba hablando de los principales puntos de lá plataforma conservadora como el único remedio efectivo contra la desintegración de la nación, que los conservadores creían que tendría lugar en medio de una invasión extranjera.

Gutiérrez Estrada se encontraba ahora en Europa viendo la realización de su profecía y más convencido que nunca de que la monarquía debía ser instalada en México. ${ }^{56}$ Describía el progreso constante del partido monárquico, en especial después de la aplastante derrota. Escribía en francés apelando a la Europa monárquica; México se sentiría halagado de recibir al vástago de alguna casa europea y de proporcionarle un trono. Europa tiene mucho que ganar en esta aventura, sostenía Gutiérrez Estrada, porque si no interviene, Estados Unidos lo hará y México perderá su comercio europeo. ${ }^{57}$ Gutiérrez Estrada podía ahora mostrar los argumentos de El Tiempo fuera del país para convencer a los estadistas europeos. No había duda de que cada segmento de la sociedad daría la bienvenida a la monarquía, se había dicho. "Los campesinos, mineros, comerciantes, industriales y todos los que alientan la nación con su trabajo piden orden, paz y libertad; demandan éstos como elementos indispensables del progreso." 58 En vez de invitar a Estados Unidos, México debería volver sus ojos a Europa, donde

\footnotetext{
${ }^{36}$ Gutiérrez Estrada, México en 1840 y en 1847 , p. 4.

57 Gutiérrrez Estrada, Le Mexique et l'Europe, París, 1847, p. 15.

58 El Tiempo, 26 de febrero de 1846 .
} 
las naciones más ilustradas (y algunas más parecidas a México que a Estados Unidos) son monarquías. ${ }^{59}$

La impresión de la derrota de 1847 hizo que los conservadores creyeran que la monarquía era más necesaria que nunca. Gutiérrez Estrada viajó de corte en corte los quince años siguientes hasta que encontró un prospecto deseable para ocupar el trono mexicano. Mientras tanto, El Universal aparecía, con algunas reservas en el tono, pero apenas disimulando bajo la superficie de cada página las propuestas monárquicas. La derrota forzó a los conservadores a comprometerse de una manera más determinante con su programa, con la monarquía como uno de sus más importantes puntos. Se hablaba menos abiertamente de la monarquía después de 1848 a causa de las dificultades para importar un príncipe en esos momentos. Era un proyecto que debía desarrollarse con lentitud en las capitales de Europa.

La amenaza de otra invasión norteamericana llevó a una racha de preocupación entre los conservadores en 1852 y 1853 en lo que respecta a la posibilidad de formar una alianza hispanoamericana. La idea era una de las favoritas de Lucas Alamán, aunque no la expuso al escribir. ${ }^{60}$ Los conservadores comenzaron a buscar socios para su empresa y se dirigieron a Chile, que había seguido en esencia una trayectoria conservadora desde su inde-

"99 lbid., 16 de febrero de 1846.

${ }^{60}$ José Vasconcelos atribuye esta idea a Alamán; es el factor principal en su creación de la leyenda de Alamán. Según Vasconcelos, Alamán continuó el sueño de Bolivar al abogar por una liga de las naciones hispanas para contrarrestar la amenaza yanqui, Bolivarismo y monroísmo, Santiago de Chile, 1937. pendencia. "Es la única ex colonia española que ha evitado los desastres sufridos por todas las otras. ${ }^{n 1}$ El Universal cantó alabanzas a Chile y describió su gran progreso material en medio de una atmósfera de orden y paz. ${ }^{62}$ América Latina debe despertar de la tontería de las ideas ultrademocráticas. Los americanos fueron descritos como los "islamitas" del siglo XIX, que tan sólo podían ser detenidos por "una alianza de todos los pueblos de origen hispánico". ${ }^{63}$ Quizá debería tenerse en cuenta hasta ser un protectorado español, decía El Universal; en verdad los invasores de 1847 habrían sido rechazados si España hubiera venido en nuestra ayuda. Durante todo 1853, El Universal continuó abogando por la alianza, pero la idea perdió terreno con la muerte de Alamán y las extravagantes divergencias de Santa Anna.

Después de diez años de ideas y política triviales, la guerra con Estados Unidos tuvo un efecto dramático sobre el curso del desarrollo mexicano durante las dos décadas siguientes. Tanto los liberales como los conservadores, viendo la impotencia de su país, reafirmaron con crecido vigor sus primeros programas para la salvación nacional. Los grandes debates del periodo $1846-1853$ predicen la violencia por venir. No resulta una sorpresa que la gran reforma de 1857 y el episodio de Maximiliano de 1863 se dieran inmediatamente después del Tratado de Guadalupe Hidalgo.

Chapel Hill, Carolina del Norte.

\footnotetext{
62 Algunos mexicanos, op. cit., p. 18.

${ }^{62}$ El Universal, 23 de julio de 1853.

${ }^{63}$ lbid., 18 de junio de 1852 .
} 


\section{SECUENCIA}

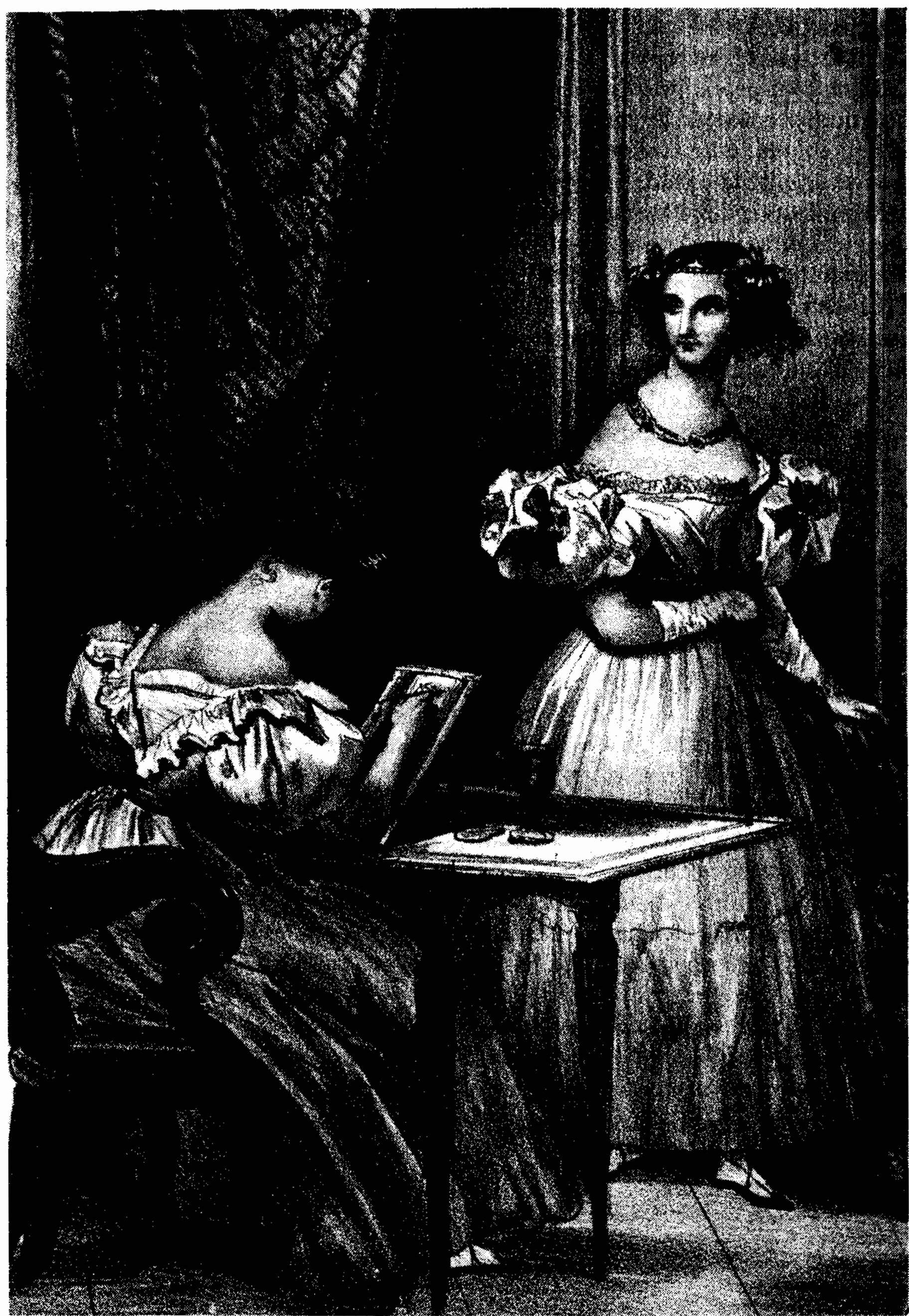

